\title{
DISTRIBUTION AND EPIDEMIOLOGICAL ASPECTS ASSOCIATED WITH ENTERIC BACTERIAL INFECTIONS IN BULGARIA
}

\author{
Y. Mitova, V. Doicheva, S. Angelova, N. Chumak \\ Department of Epidemiology, Medical University - Sofia, Bulgaria
}

\begin{abstract}
Enteric bacterial infections are characterized by the location of causative agents in the intestine and their distribution in the environment with excrements. Intestinal bacterial infections in Bulgaria are caused by Salmonella spp., Shigella spp., E. coli, Campilobacter spp., Yesinia enterocolitica. For the period 2016-2018, the incidence rate of salmonellosis in Bulgaria was close to that of the European Union (EU). It was 11,21 per 100000 population in 2017 (14,6\%ooo in the EU). The incidence rate of typhoid fever in Bulgaria was lower than that in the EU for the period 2016-2018-0.01-0.03 per 100000 population. Bulgaria had the highest rate of shigellosis in the EU. For the period 2016-2018 it was between 3,33\%ooo and 4,07 per 100 000. The incidence of Campylobacter infection in Bulgaria during the period 2016-2018 was between 2,72\%ooo and 2,88\%ooo and was lower than the EU average. Data on yersiniosis in Bulgaria is incomplete. For the period 2016-2018, 36 cases were reported. E. coli enteritis had a higher average annual notification rate in the 0 to 1 age group (142,65 cases per 100 000 population). The main means of controlling intestinal infection are sanitary measures that prevent the transmission of pathogenic microorganisms with food, water, insects, contaminated hands, etc.
\end{abstract}

Key words: enteric bacterial infections, distribution, average annual incidence rates, seasonal variations, age groups

Corresponding author: Assoc. Prof. Dr. Yordanka Mitova-Mineva, e-mail:drmitova@mail.bg

\section{INTRODUCTION}

ntestinal infections cause significant morbidity and mortality worldwide, especially among children. Infectious agents usually spread by faecal-oral route, which includes the ingestion of faecal contaminated water or food and person to person transmission after direct contact with infected faeces. Intestinal bacterial infections in Bulgaria are caused by Salmonella spp. (including S. typhi), Shigella spp., E. coli, Clostridium botulinum, Campilobacter spp., Yesinia enterocolitica. At present, it is of interest to better define the global burden of diarrheal diseases and to implement programs that use specific interventions for specific microbes. Given that disease distribution varies in space and time, epidemiological patterns can be investigated 
through routine monitoring data. The purpose of this study is to describe the incidence of intestinal diseases in Bulgaria from 2016 to 2018. The data is compared with that from other countries in the European Union (EU).

\section{MATERIALS AND METHODS}

Data on intestinal bacterial infections (shigellosis/ dysentery, typhoid fever, salmonellosis, E. coli enteritis (including Shiga-like-toxin-producing E. coli (STEC) infections), yersiniosis, salmonellosis, campylobacteriosis, botulism, listeriosis, enterocolitis) was obtained from the National Center for Public Health and Analysis, Bulgaria. This retrospective study uses data for 2016-2018. The data was taken from notifications of intestinal bacterial diseases, as published in report no. 85 on the recording of acute infectious disease. To determine the magnitude of each disease, the average annual incidence rates (IR) of 100000 population were calculated. The incidence rate for each region was calculated on the basis of officially confirmed cases of intestinal bacterial diseases, divided by the population estimates for each region for the respective year. This study focuses on the analysis of circulating intestinal bacteria, their prevalence and epidemiological characteristics of laboratory confirmed cases for 2016-2018.

Statistical analysis. In the processing and analysis of the collected materials the complex epidemiological method was applied together with some methods of the alternative analysis.

\section{RESULTS}

During the study period, 49619 common bacterial enteric diseases (16 540 per year) were reported nationally during the study period. Most of these cases of confirmed etiology were caused by Campylobacter, E. coli, Shigella or Salmonella species (Table 1).

The incidence rate of salmonellosis in Bulgaria was 10,04 per 100000 population (\%ooo) in 2016, 11,21 per 100000 in 2017 and 8,31 per 100000 in 2018. The typhoid fever incidence rate in Bulgaria was lower than that in the EU for the period 2016-2018 - 0.010.03 per 100000 . Bulgaria had the highest level of shigellosis morbidity in the EU. For the period 20162018 it ranged between 3,33 and 4,07 per 100000

Table 1. Number of Cases, Number of Deaths, Incidence Rate (per 100000 population), Mortality Rate (per 100000 population), Case Fatality Rate (\%) of Enteric Bacterial Infections, Bulgaria, 2016-2018

\begin{tabular}{|c|c|c|c|c|c|c|c|c|c|c|c|c|c|c|c|}
\hline Year & & & 016 & & & & & 17 & & & & & 18 & & \\
\hline Diagnoses & 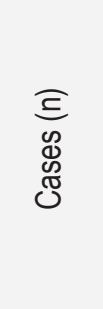 & 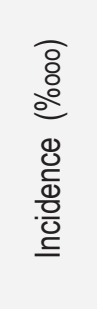 & 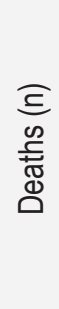 & 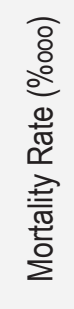 & 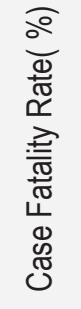 & 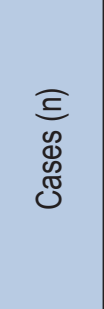 & 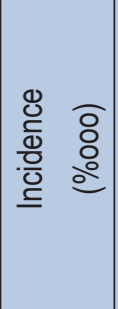 & 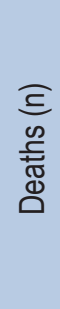 & 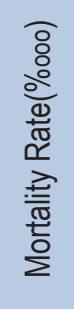 & 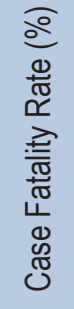 & 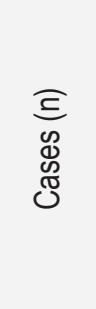 & 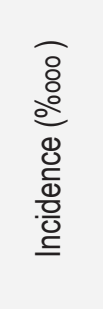 & 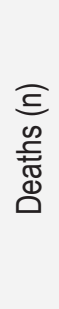 & 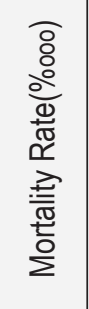 & 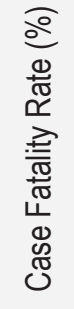 \\
\hline Abdominal typhus & 1 & 0,01 & 0 & 0 & 0 & 2 & 0,03 & 0 & 0 & 0 & 1 & 0,01 & 0 & 0 & 0 \\
\hline Salmonellosis & 718 & 10,04 & 1 & 0,01 & 0,14 & 796 & 11,21 & 1 & 0,01 & 0,13 & 586 & 8,31 & 2 & 0,03 & 0,34 \\
\hline Shigellosis & 291 & 4,07 & 0 & 0 & 0 & 308 & 4,34 & 0 & 0 & 0 & 235 & 3,33 & 0 & 0 & 0 \\
\hline E. coli enteritis & 360 & 5,03 & 0 & 0 & 0 & 240 & 3,38 & 0 & 0 & 0 & 307 & 4,35 & 0 & 0 & 0 \\
\hline $\begin{array}{l}\text { Campylobacte- } \\
\text { riosis }\end{array}$ & 202 & 2,82 & 0 & 0 & 0 & 196 & 2,76 & 0 & 0 & 0 & 192 & 2,72 & 0 & 0 & 0 \\
\hline Botulism & 3 & 0,04 & 0 & 0 & 0 & 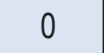 & 0 & 0 & 0 & 0 & 0 & 0 & 0 & 0 & 0 \\
\hline Enterocolitis & 16786 & 234,7 & 14 & 0,2 & 0,08 & 14650 & 206,28 & 25 & 0,35 & 0,2 & 13704 & 194,38 & 22 & 0,31 & 0,16 \\
\hline Yersiniosis & 10 & 0,14 & 0 & 0 & 0 & 17 & 0,24 & 0 & 0 & 0 & 9 & 0,13 & 0 & 0 & 0 \\
\hline Listeriosis & 5 & 0.07 & 2 & 0.03 & 40 & 0 & 0 & 0 & 0 & 0 & 0 & 0 & 0 & 0 & 0 \\
\hline
\end{tabular}


population. The incidence of Campylobacter infection in Bulgaria in 2016-2018 was between 2,72\%ooo and 2,88 per 100000 . The E. coli enteritis incidence rate was about 4 per 100000 population.

There were 45140 (92\% of them without isolation of the causative agent) reported cases of enterocolitis in Bulgaria for the period 2016-2018, including 61 deaths. Etiologically unchecked and unverified cases of enterocolitis complicated the specification of counter-epidemic measures and even patients' therapies.

Some seasonal patterns were recognised. There were clear seasonal differences in the number of reported cases of bacterial intestinal disease, with the number of cases increasing during the summer months, reaching their peak in July, August and September, and then decreasing (Fig. 1).

In 2018, the highest incidence of shigellosis was observed in children under five years of age. The incidence rate in 1-4 age group was the highest, with 26,14 cases per 100000 population. There were no differences in the overall rates between males and females (Table 2a).

The incidence of Salmonella infections was the highest in 1-4 age group $(80,69$ per 100000$)$, followed by $0-1$ year olds ( 61,14 per 100000 ) (Table $2 b$ ). Men (316 cases) predominated over women (270 cases) during the period.

Table 2a. Incidence rate of Shigella infections, reported by age group and sex

\begin{tabular}{|l|l|l|l|}
\hline $\begin{array}{l}\text { Age } \\
\text { group, } \\
\text { years }\end{array}$ & $\begin{array}{l}\text { Female } \\
\text { (Incidents per } \\
100 \text { 000) }\end{array}$ & $\begin{array}{l}\text { Male } \\
\text { (Incidents } \\
\text { per 100 000) }\end{array}$ & $\begin{array}{l}\text { Total } \\
\text { (Incidents } \\
\text { per 100 000) }\end{array}$ \\
\hline 0 & 16,09 & 21,4 & 18,81 \\
\hline $1-4$ & 24,91 & 27,3 & 26,14 \\
\hline $5-9$ & 7,66 & 16,14 & 12,02 \\
\hline $10-14$ & 10,71 & 7,72 & 9,17 \\
\hline $15-19$ & 4,6 & 3,11 & 3,83 \\
\hline $20-24$ & 2,54 & 0,6 & 1,54 \\
\hline $25-29$ & 1,39 & 0,87 & 1,12 \\
\hline $30-34$ & 0,86 & 0,81 & 0,83 \\
\hline $35-39$ & 2,08 & 1,93 & 2 \\
\hline $40-44$ & 1,12 & 0,35 & 0,73 \\
\hline $45-49$ & 0,79 & 0,38 & 0,58 \\
\hline $50-54$ & 1,74 & 2,15 & 1,94 \\
\hline $55-59$ & 1,62 & 0,85 & 1,24 \\
\hline $60-64$ & 1,54 & 0,44 & 1,03 \\
\hline $65+$ & 1,47 & 1,01 & 1,28 \\
\hline Total & 3,25 & 3,42 & 3,33 \\
\hline
\end{tabular}

E. coli enteritis had a higher average annual notification rate in $0-1$ age group $(142,65$ cases per 100000 people), followed by $1-4$ age group $(47,36$ cases per 100 000) (Table 2c).

In 2018, the highest average annual incidence of reported Campylobacter infections refered to 0-1 age group (26.65 per 100000 ), followed by $1-4$ age group (25.38 per 100 000) (Table 2d).

This study shows that reported shigellosis/dysentery, salmonellosis, E. coli enteritis and campylobacteriosis have different geographic features in Bulgaria, and their prevalence and distribution can be linked to a combination of different environmental factors.

Blagoevgrad region showed the highest average incidence of Shigellosis in 2018 (22,09\%ooo) with 68 infected individuals (Fig. 2). Statistically significant trend of increase or decrease during the investigated period was not observed for any of the regions. Ruse and Shumen regions showed higher average incidence of Salmonellosis (with a 19,9 and 14,45 infected persons respectively per 100000 population (Fig. 3). The highest incidence of E. coli enteritis was reported for Silistra region in $2018-31,6 \%$ ooo (Fig. 4). About 1/4 (27\%) of Campylobacteriosis in 2018 were reported from Yambol region - incidence rate $31,60 \%$ ooo (Fig. 5).

Table $\mathbf{2 b}$. Incidence rate of Salmonella infections, reported by age group and sex

\begin{tabular}{|l|l|l|l|}
\hline $\begin{array}{l}\text { Age } \\
\text { group, } \\
\text { years }\end{array}$ & $\begin{array}{l}\text { Female } \\
\text { (Incidents per } \\
\mathbf{1 0 0} 000)\end{array}$ & $\begin{array}{l}\text { Male } \\
\text { (Incidents } \\
\text { per 100 000) }\end{array}$ & $\begin{array}{l}\text { Total } \\
\text { Incidents } \\
\text { per 100 000) }\end{array}$ \\
\hline 0 & 41,82 & 79,49 & 61,14 \\
\hline $1-4$ & 74,74 & 86,34 & 80,69 \\
\hline $5-9$ & 21,79 & 21,71 & 21,75 \\
\hline $10-14$ & 8,82 & 7,72 & 8,25 \\
\hline $15-19$ & 4,60 & 3,11 & 3,83 \\
\hline $20-24$ & 3,81 & 3,58 & 3,69 \\
\hline $25-29$ & 1,85 & 2,18 & 2,02 \\
\hline $30-34$ & 3,45 & 3,63 & 3,54 \\
\hline $35-39$ & 2,49 & 3,86 & 3,2 \\
\hline $40-44$ & 2,62 & 1,06 & 1,82 \\
\hline $45-49$ & 2,77 & 4,14 & 3,47 \\
\hline $50-54$ & 6,09 & 5,16 & 5,62 \\
\hline $55-59$ & 2,03 & 5,92 & 3,93 \\
\hline $60-64$ & 3,08 & 7,46 & 5,13 \\
\hline $65+$ & 4,29 & 4,86 & 4,52 \\
\hline Total & 7,44 & 9,23 & 8,31 \\
\hline & & & \\
\hline
\end{tabular}


Table 2c. Incidence rate of E.coli enteritis, reported by age group and sex

\begin{tabular}{|l|l|l|l|}
\hline $\begin{array}{l}\text { Age } \\
\text { group, } \\
\text { years }\end{array}$ & $\begin{array}{l}\text { Female } \\
\text { (Incidents } \\
\text { per 100 000) }\end{array}$ & $\begin{array}{l}\text { Male } \\
\text { (Incidents } \\
\text { per 100 000) }\end{array}$ & $\begin{array}{l}\text { Total } \\
\text { (Incidents } \\
\text { per 100 000) }\end{array}$ \\
\hline 0 & 119,03 & 165,1 & 142,65 \\
\hline $1-4$ & 49,83 & 45,02 & 47,36 \\
\hline $5-9$ & 8,83 & 5,57 & 7,15 \\
\hline $10-14$ & 1,89 & 1,78 & 1,83 \\
\hline $15-19$ & 4,60 & 2,48 & 3,51 \\
\hline $20-24$ & 0,64 & 0 & 0,31 \\
\hline $25-29$ & 0,46 & 0 & 0,22 \\
\hline $30-34$ & 3,02 & 0,4 & 1,67 \\
\hline $35-39$ & 2,08 & 0,77 & 1,4 \\
\hline $40-44$ & 1,50 & 0,71 & 1,09 \\
\hline $45-49$ & 0,79 & 1,5 & 1,16 \\
\hline $50-54$ & 0,43 & 0 & 0,22 \\
\hline $55-59$ & 1,62 & 0,85 & 1,24 \\
\hline $60-64$ & 0,38 & 0,44 & 0,41 \\
\hline $65+$ & 0,56 & 1,01 & 0,74 \\
\hline Total & 4,33 & 4,38 & 4,35 \\
\hline & & & \\
\hline
\end{tabular}

\begin{tabular}{|l|l|l|l|}
\hline $\begin{array}{l}\text { Age group, } \\
\text { years }\end{array}$ & $\begin{array}{l}\text { Female } \\
\text { (Incidents } \\
\text { per 100 000) }\end{array}$ & $\begin{array}{l}\text { Male } \\
\text { (Incidents } \\
\text { per 100 000) }\end{array}$ & $\begin{array}{l}\text { Total } \\
\text { (Incidents } \\
\text { per 100 000) }\end{array}$ \\
\hline 0 & 12,87 & 39,75 & 26,65 \\
\hline $1-4$ & 21,02 & 29,52 & 25,38 \\
\hline $5-9$ & 8,83 & 10,02 & 9,44 \\
\hline $10-14$ & 3,78 & 7,72 & 5,81 \\
\hline $15-19$ & 1,32 & 3,11 & 2,24 \\
\hline $20-24$ & 3,18 & 0 & 1,54 \\
\hline $25-29$ & 0,93 & 0 & 0,45 \\
\hline $30-34$ & 0,00 & 0,4 & 0,21 \\
\hline $35-39$ & 0,42 & 0,39 & 0,4 \\
\hline $40-44$ & 0,75 & 0,35 & 0,55 \\
\hline $45-49$ & 1,19 & 1,13 & 1,16 \\
\hline $50-54$ & 2,17 & 1,29 & 1,73 \\
\hline $55-59$ & 0,81 & 0,85 & 0,83 \\
\hline $60-64$ & 2,69 & 0,44 & 1,64 \\
\hline $65+$ & 0,56 & 0,84 & 0,67 \\
\hline Total & 2,37 & 3,1 & 2,72 \\
\hline
\end{tabular}

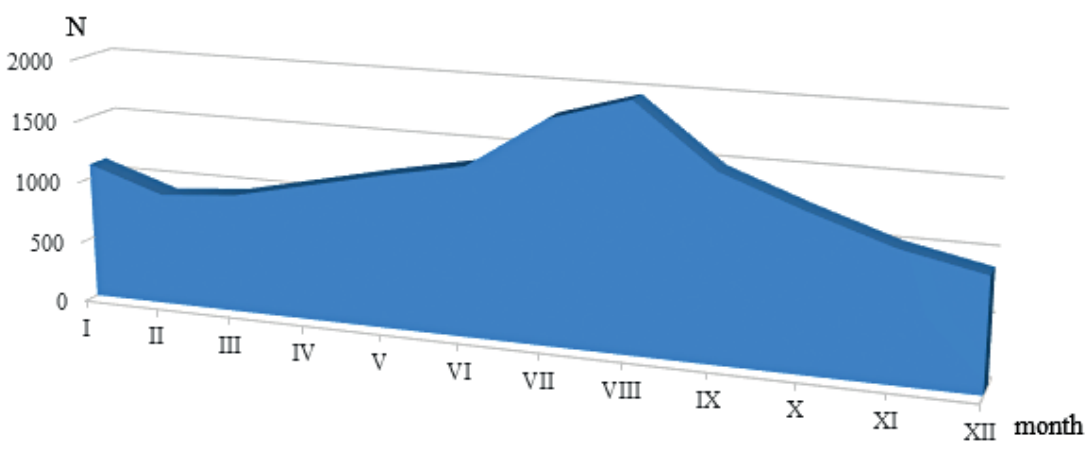

Fig. 1. Enteric diseases by month of report, Bulgaria, 2018

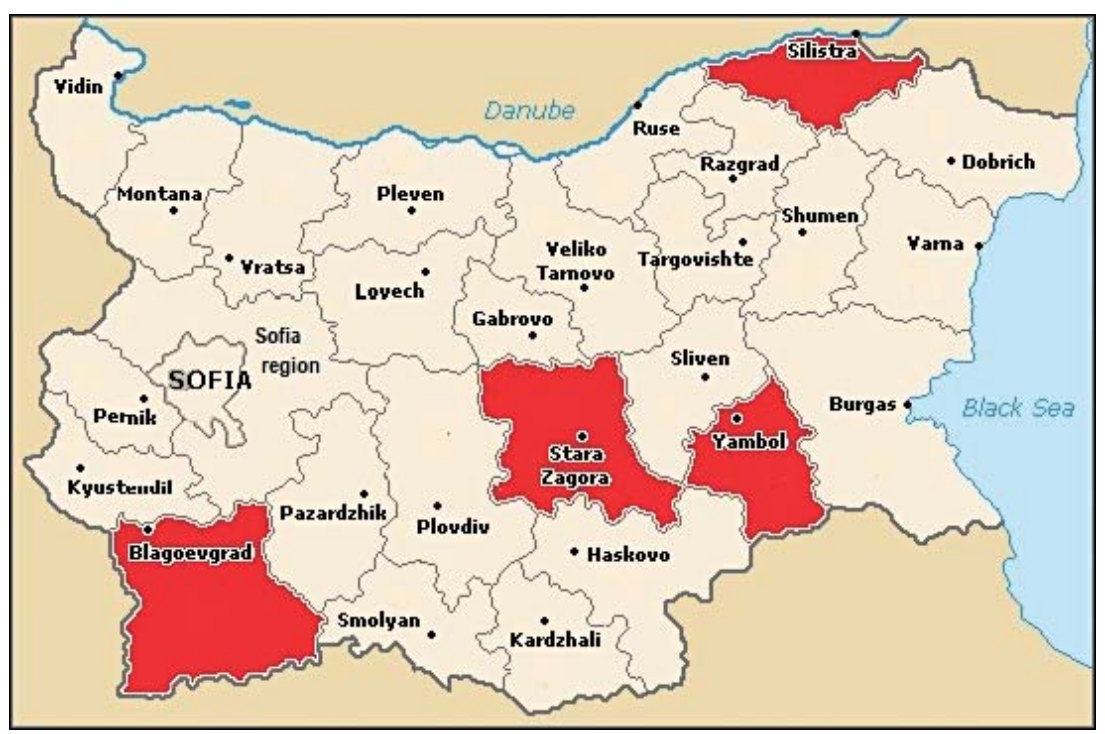
affected by Shigellosis, 2018
Fig. 2. Regions in Bulgaria most 


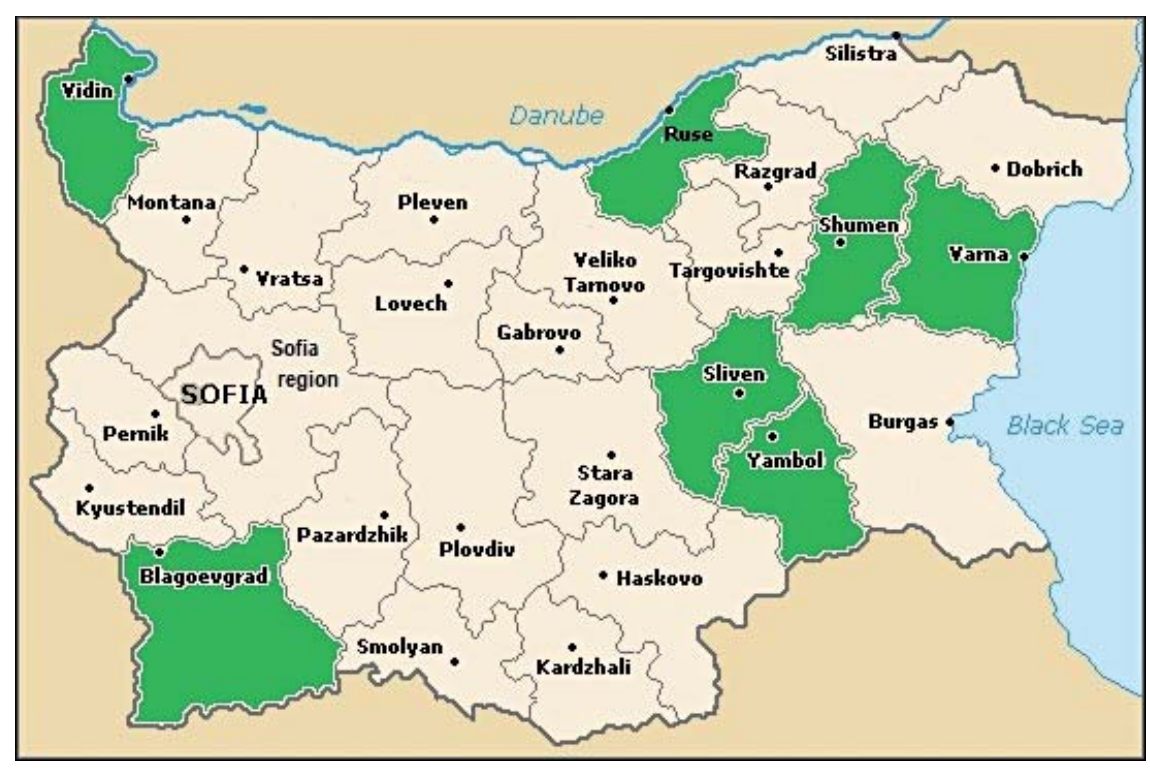

Fig. 3. Regions in Bulgaria most affected by Salmonellosis, 2018

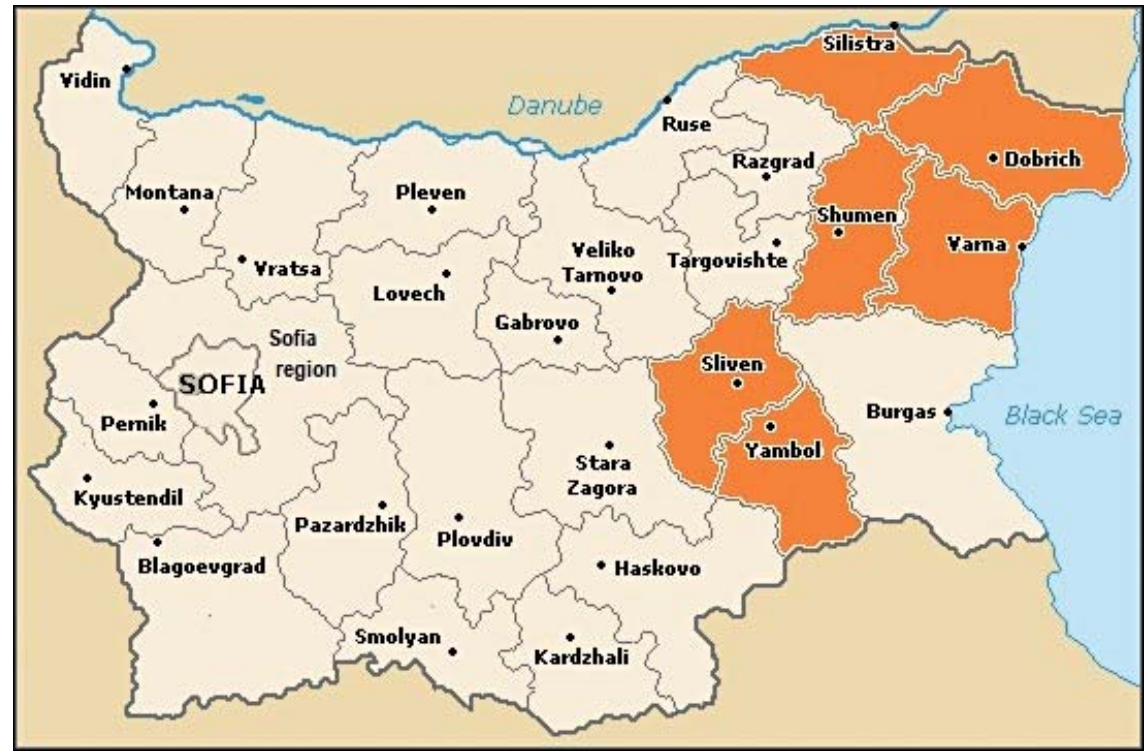

Fig. 4. Regions in Bulgaria most affected by E. coli enteritis, 2018

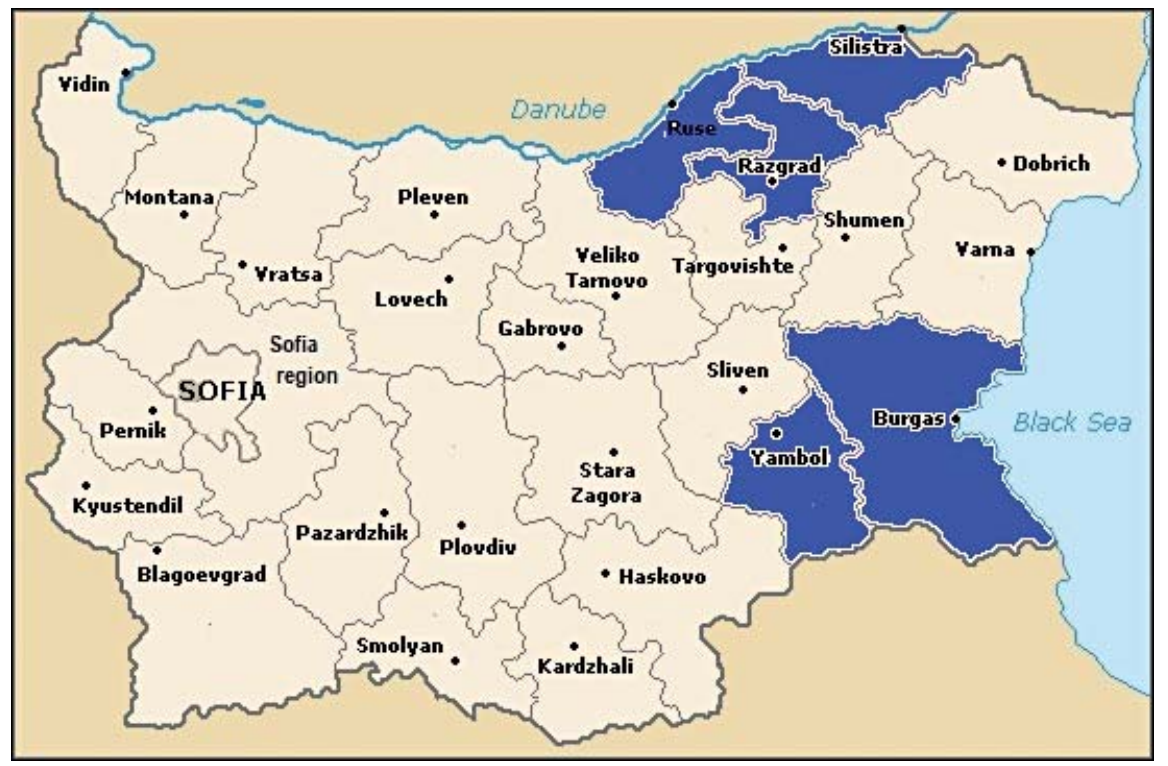

Fig. 5. Regions in Bulgaria most affected by Campylobacteriosis, 2018 


\section{DISCUSSION}

The typhoid fever was endemically widespread in Bulgaria in the beginning of last century. A sharp incidence drop was observed during the period 19391940 , after the immunization of the population with inactivated typhoid vaccine in 1931. After 1970, sporadic incidents were registered (two epidemic outbreaks were filed in 1983 and 1991, with 21 and 14 infected respectively) [4].

Four cases of typhoid fever were registered during the period 2016-2018. (Table 1) In each one of the years, the incidence rate was $0,01 \%$ ooo, 0,03\%ooo, and 0,01\%ooo respectively. According to 2016 European Centre for Disease Prevention and Control (ECDC) data, 1116 incidents of typhoid fever and paratyphoid fever were registered in the European Union, the incidence rate being $0,33 \% 000$. The highest incidence rates were registered in France $(0,69 \%$ ooo, 222 infected), the UK $(0,70 \%$ ooo, 456 infected), Spain, Denmark and Norway. Epidemiological studies indicate that $82,5 \%$ of cases were related to traveling to typhoid-endemic countries - India, Pakistan, Bangladesh, Senegal and others [2].

The prevalence of salmonellosis (with the exception of typhoid and paratyphoid fever) was facilitated by intensive international trade in animals, protein crops, poultry, etc. In 2017, the highest incidence rate in the EU was reported in Slovenia - 106,51\%ooo (5 789 infected), followed by Lithuania - 35,25\%оoo (1 004 infected), Croatia - 29,9\%ooo (242 infected) and Finland $-27,89 \%$ ooo (1 535 infected). The incidence of salmonellosis in Bulgaria for the period 2016-2018 was $20,4 \%$ ooo, $11,22 \%$ oo and $8,31 \%$ ooo respectively, and was lower than the EU average. One death was recorded in 2016 (case fatality rate of $0,14 \%$ ), one in 2017 (0,13\%), and two in 2018 (0,34\%). In 2017, 156 deaths were registered in the EU countries, representing a case fatality rate of $0,2 \%$. For the year in question, the highest number of deaths was registered in the United Kingdom - 55, a case fatality rate of $0,6 \%[1]$.

E.coli enteritis is a widespread disease, caused by pathogen Escherihia coli. For the period 2016-2018 - 360, 240 and 307 cases of E.coli enteritis respectively, were reported in Bulgaria. The spread of Shiga-like toxin producing E.coli (STEK) in Bulgaria was lower than in the other EU countries. Single cases were registered. The STEK incidents registered in the EU were 6073 , incidence rate $-1,67 \%$ ooo, case fatality rate $-0,50 \%$. The highest incidence rate was registered in Ireland - 16,62 and Germany - 2,5 per 100000 population.
Bulgaria is one of the EU countries with the highest shigellosis incidence rate. There were 291 cases registered in 2016 (incidence rate of 4,07 per 100000 population), 308 cases in 2017 (incidence rate of $4,34 \%$ ooo), and 235 case in 2018 (incidence rate of $3,33 \% \circ 00$ ). No death cases were reported. Shigellosis disease rate in EU countries was $1,66 \%$ ooo. There were 4 death cases registered (case fatality rate of $0,1 \%$ ) [1].

Campylobacter infection is one of the most commonly identified bacterial causes of acute gastroenteritis worldwide. The Campylobacter infection incidence rate in Bulgaria during the period 2016-2018 is shown in table 1 . There is no significant difference in the number of filed cases. The highest disease rate was registered in $2016-2,88 \%$ ooo.

There were 246158 Campylobacter infection cases registered in the European Union in 2017, disease rate $-64,54$ per 100000 . Belgium was the country with the highest disease rate $-76,19 \%$ oo [1].

Yersiniosis is an acute infectious disease, which is characterized by gastroenteritis or enterocolitis. It's course might include also mesenteric lymphadenitis. The Yersiniosis data in Bulgaria is partial. For the period 2016-2018, 36 cases were registered. The highest incidence rate was filed in $2017-0,24 \%$ ooo. In 2017, 6823 cases of Yersiniosis were reported in the EU [1].

Listeriosis is a bacterial disease usually manifested as meningoencephalitis and/or septicemia in newborn children and adults. Those at the highest risk are neonates, the elderly, immunocompromised individuals, pregnant women, alcoholics, cirrhotic or diabetic adults. About $30 \%$ of clinical cases occur within the first 3 weeks of life [3]. In 2017, 2480 confirmed cases of listeriosis were reported by EU countries, with an overall notification rate of 0,48 per 100000 population. Germany and France had the highest numbers of reported cases (726 and 370 respectively). The highest incidence rates were observed in Germany, Sweden and Finland. The highest numbers of cases were reported in July, August and September [1].

For the period of 2016-2018, five cases were registered in Bulgaria, the overall case fatality rate for them was $40 \%$.

Botulism is widespread, but it is more common in countries where there is high consumption of canned food, cold cuts and fish. There were 3 cases registered in Bulgaria in 2016. No botulism cases were filed in 2017 and 2018 and there were no death cases reported for the period. Eighty-four cases of botulism were reported in the EU in 2017, with an incidence of 
0,02 per 100000 population. The highest number of incidents was registered in Italy -21 cases [1].

The "enterocolitis" diagnosis includes intestinal infections with different etiology (viral or bacterial) and often with no microbiological or serological proof of diagnosis. There were 16786 cases reported in Bulgaria in 2016 (incidence rate 234,65 per 100 000), 14 650 in 2017 (incidence rate 206,28\%ooo), and 13704 in 2018 (incidence rate 194,38\%ooo). There were 14 deaths in 2016 (0,08\% case fatality rate), 25 in 2017 $(0,17 \%$ case fatality rate), and 22 in $2018(0,16 \%)$.

The high number of reported cases of enterocolitis with unknown etiology suggests improving intestinal bacterial infections diagnosis in Bulgaria, which is the most important factor for more efficient control and prevention.

\section{CONCLUSION}

Communicable diseases kill more than 14 million people each year, mainly in the developing world. In these countries, approximately $46 \%$ of all deaths are due to communicable diseases, and $90 \%$ of these deaths are attributed to acute enteric and respiratory infections of children, AIDS, tuberculosis, malaria, and measles [3].
It is not possible to provide a specific set of guidelines applicable to all situations. General measures to improve hygiene are important but often difficult to implement because of their cost. An organized effort to promote careful hand washing with soap and water is the single most important control measure to decrease transmission rates in most settings. In the context of the results obtained, it is necessary to raise the health knowledge of children and adolescent about enteric infections and to improve the essential hygienic habits.

Disclosure Summary: The authors have nothing to disclose.

\section{REFERENCES}

1. Disease data from ECDC Surveillance Atlas, Available from: https://ecdc.europa.eu/en/ surveillance-and-disease-data/atlas.

2. European Centre for Diseases Prevention and Control. Typhoid and paratyphoid fever for 2016, Stockholm: ECDC, 2018.

3. Heymann D L. Control of Communicable Diseases Manual (CCDM), the 18th revision, 2008.

4. Iliev B., Mitov G. Epidemiology of infectious and noninfectious diseases, Sofia, Med Fizkult, 1994.

Received: March, 2019 - Accepted: May, 2019 